\title{
Scientific aspects of the study of the protein- carbohydrate raw materials biomodification process in the production of functional food products
}

\author{
Larisa Enalyeva ${ }^{1, *}$, Dmitry Rudoy ${ }^{1}$, Andrey Alekseyev ${ }^{2}$, Tatyana Tupolskih ${ }^{1}$, and \\ Vyacheslav Lodyanov ${ }^{1}$ \\ ${ }^{1}$ Don State Technical University, 344003, Gagarin sq., 1, Rostov on Don, Russia \\ ${ }^{2}$ Don State Agrarian University, 346493, 24, vil. Persianovskiy, Russia
}

\begin{abstract}
At present, the development of new technologies in the food industry and the creation of a wide range of qualitatively new products with a directed change in the chemical composition and properties is an important direction, which contributes to improve population's nutritional system. Particularly, at present the introduction of resource-saving, importsubstituting technologies into production, which allow the rational use of secondary raw materials, preserve the country's food security and expand the range of functional food products, is important. The purpose of the research is the possibility of joint use of raw milk, raw cream, milk processing by-products, biologically active plant raw materials and the development on their basis of a technology for an enriched cheese product of the "Ricotta" type with functional properties in order to introduce import-substituting technologies, improve the structure nutrition of the population. The objects of research were raw milk, cheese whey, fermented cheese whey, milk-whey mixture, barley malt extract. The most optimal time of biomodification, the concentration of the introduced biologically active additive, the amount of proteolysis have been established. The need for biomodification by a consortium of probiotic bacteria in order to improve the nutritional value of the product.
\end{abstract}

\section{Introduction}

At present, the development of new technologies in the food industry and the creation of a wide range of qualitatively new products with a directed change in the chemical composition and properties is an important direction that contributes to the improvement of the population's nutritional system. Particularly important at present is the introduction of resource-saving, import-substituting technologies into production, which allow the rational use of secondary raw materials, preserve the country's food security and expand the range of functional food products. [1-2].

\footnotetext{
* Corresponding author: enaleva@yandex.ru
} 
Technologies that improve the taste and food safety of the product, increasing the profitability of production in modern conditions, will be key to ensure the efficient operation of the cheese-making enterprise, its profitability, and the ability to withstand increasing competition. In addition, the assortment line of soft cheeses is much wider and opens up great opportunities for new creative solutions. These are the principles that soft cheese technologies meet [3-5].

Soft cheese - is a high-quality protein food product obtained by enzymatic, acidic, acidrennet or thermoacid coagulation of specially prepared milk, processing of a curd, forming a cheese mass with or without subsequent maturation [6-7].

In modern scientific literature, there is no data on the use of malt extracts in production of combined cheese products. Therefore, it is advisable to develop a technology for a cheese product using a biologically active additive [8-9].

The relevance of the work lies in the development of technology for a cheese product like "Ricotta" using a biologically active phyto-extract with parapharmaceutical properties and techno-technological functionality, which will expand the range of specialized food products.

The purpose of this work is the possibility of joint use of raw milk, raw cream, milk processing by-products, biologically active plant raw materials and the development on their basis of a technology for an enriched cheese product like "Ricotta" with functional properties in order to introduce import-substituting technologies, improve the structure nutrition of the population and the implementation of the requirements of the Technical Regulations of the Customs Union TR CU 027/2012 and TR CU 033/2013.

Based on this goal, a working hypothesis was formed, which is based on the assumption that malt extract will have a positive effect on the structure formation of a thermoacid cheese product due to the content of free amino acids in it, which are part of proteins that act as emulsifiers and stabilizers of the formed systems, vitamins, macro and trace elements, flavonoids, enzymes, etc. Analysis of the properties of malt extracts indicates that malt extracts are healthy, natural, palatable, multi-purpose food ingredients. They are able to significantly increase the taste, biological value and pleasure of consuming a wide variety of foods in a natural way [10-12].

The laws of a market economy place the cheese-making industry in a tough competition. In this situation, only scientifically grounded flexible assortment policy and high quality of products will help enterprises to take their rightful place in the cheese market [13-15].

The studies were carried out in the laboratory of biochemical and spectral analysis of food products of the Department of Technology and Technology of Food Production FSFEI HE «DSTU».

\section{Objects and research methods}

The main objects of research were: raw milk, cheese whey, fermented cheese whey, milkwhey mixture, barley malt extract.

The research methodology provided for the production of barley malt extract. The development of the malt extract technology was carried out in two ways. According to the first method, dry malt, ground in a colloid mill, is mixed with water in a ratio of 1: 4 , heated to a temperature of $40^{\circ} \mathrm{C}$ and held for 30 minutes. (the optimum action of enzymes, the destruction of non-starch polysaccharides, the accumulation of inorganic phosphates), then up to $63^{\circ} \mathrm{C}$ and incubated for 30 minutes, then up to $70^{\circ} \mathrm{C}$ and incubated for 30 minutes, then up to $72^{\circ} \mathrm{C}$ and incubated for 30 minutes. Heating and holding at different temperatures is carried out for the complete extraction of amylolytic and proteolytic enzymes that affect carbohydrates and proteins break them down to mono- and 
disaccharides, peptides, amines, amides, individual amino acids, accumulation of inorganic phosphates, organic acids (succinic acid, etc.) etc.), biologically active substances (mesoinoside), etc. The saccharified extract is heated to $77^{\circ} \mathrm{C}$ and filtered.

The second technological scheme for the preparation of barley malt extract is subdivided into 1 st and 2nd decoction of malt. First is decoction. Dry malt, ground in a colloid mill, is mixed with water in a ratio of 1:4 and heated to a temperature of $40^{\circ} \mathrm{C}$ with an exposure of 30 minutes, then heated to a temperature of $52^{\circ} \mathrm{C}$, held for $15-30$ minutes, heated to a temperature of $63^{\circ} \mathrm{C}$, held for $20-30$ minutes, heated to a temperature of $70-72^{\circ}$ $\mathrm{C}$, held for 20-30 minutes, heated to a temperature of $100^{\circ} \mathrm{C}$, held for 15-30 minutes. Second is decoction. Cooled to a temperature of $62-63^{\circ} \mathrm{C}$, held for $10-15$ minutes, heated to a temperature of $70-72^{\circ} \mathrm{C}$, held for 20 minutes, heated to a temperature of $100^{\circ} \mathrm{C}$, held for 10-20 minutes, cooled to $70^{\circ} \mathrm{C}$, incubated for 30 minutes, then heated to a temperature of $72^{\circ} \mathrm{C}$ and incubated until complete saccharification - 30 minutes. Heating and holding at different temperatures is carried out for the complete extraction of amylolytic and proteolytic enzymes that act on carbohydrates and proteins break them down to mono- and disaccharides, peptides, amines, amides, individual amino acids, there is an accumulation of inorganic phosphates, organic acids (succinic acid, etc.) etc.), biologically active substances (mesoinoside), etc. The saccharified extract is heated to $77^{\circ} \mathrm{C}$ and filtered.

There is a relationship between the $\mathrm{pH}$ value and the percentage of saccharification, presented in table 1 .

Table 1. The relationship between $\mathrm{pH}$ and the percentage of saccharification

\begin{tabular}{|c|c|c|c|c|c|c|}
\hline $\begin{array}{c}\text { № in } \\
\text { order }\end{array}$ & Indicator name & \multicolumn{5}{|c|}{ Indicator values } \\
\hline 1 & The quantity of pH & 6.08 & 5.86 & 5.64 & 5.42 & 5.19 \\
\hline 2 & Saccharification percentage & 72.7 & 76.5 & 77.0 & 77.4 & 69.9 \\
\hline
\end{tabular}

As a result of the studies, it was found that the $\mathrm{pH}$ value at the end of the technological cycle of the first technological scheme was 5.42, which corresponds to $77.4 \%$ saccharification. The $\mathrm{pH}$ value at the end of the technological cycle according to the second technological scheme was 5.86, which corresponds to $76.5 \%$ saccharification. Thus, the most rational use of technological scheme №1 in the production of malt extract, since the percentage of saccharification at the end of the technological cycle is higher than in the production of malt extract according to technological scheme №2, the destruction of nonstarch polysaccharides, the accumulation of inorganic phosphates, organic acids, etc. occur more intensively.

The functional and technological properties of barley malt extract were determined depending on the value of proteolysis, symbiotic activity, organoleptic parameters and the index of lactic fertility.

Barley Malt Extract and Probiotic Microflora Consortium (L.acidophilus, L.bulgaricus, L.casei, L.helveticus, L.lactis, L.plantarum, Prpb.freudenreichii sspcremanii, St.termophilus, Subp.ramnosus) in different percentages were added to the finished cheese mass in order to preserve the functional properties of the ingredients introduced and improve the biological value of the finished product.

Determination of the amount of proteolysis is an important indicator of the biological value of cheeses and cheese products, because as a result of the cleavage of protein molecules under the action of the enzymes of the added additive, the amount of free amino acids, nitrogenous substances, amines, amides, organic acids, peptides increases, which undoubtedly improves the organoleptic characteristics of the product (soft, delicate consistency, slightly yellowish color) and the assimilation of milk protein by the human body ( individual amino acids, amines, amides are processed by the body's enzyme system more easily than a dense clot of Caseinate Calcium Phosphate Complex (CCPhC)). 
Determine the amount of proteolysis by the Shilovich method. The method is based on changing the buffering capacity of the soluble part of the cheese during the ripening process. With an increase in the soluble decomposition products of proteins, the buffer properties of the soluble part of the cheese increase, which are most clearly revealed during titration with alkali. A strong increase in buffering in the $\mathrm{pH}$ range of 8-10 is due to the fact that protein breakdown products are titrated within these $\mathrm{pH}$ ranges, the amount of which increases with cheese ripening. Buffering is calculated from the difference in the number of milliliters $0.1 \mathrm{~N}$ alkali solution used for titration of $10 \mathrm{ml}$ of an aqueous extract with indicators thymolphthalein and phenolphthalein.

For the study, 5 samples of the cheese product $(60 \mathrm{~g}$ each) were prepared with the addition of various percentages of barley malt extract (SES) $(5-25 \%)$ and $2 \%$ of the consortium of probiotic microflora to the cheese mass. To ripen the cheese mass, the samples were placed in a thermostat at a temperature of $18^{\circ} \mathrm{C}$ for 6 hours.

\section{Results and discussion}

The results of the change in the amount of proteolysis depending on the dose of the introduced functional ingredient are presented in Table 2.

Table 2. Determination of the proteolytic activity of the added additive

\begin{tabular}{|c|c|c|c|c|c|}
\hline 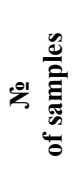 & 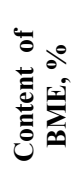 & $\stackrel{f}{E}$ & $\begin{array}{l}\text { The amount of alkali, } \\
\text { used for titration with } \\
\text { thymolphthalein, ml }\end{array}$ & $\begin{array}{l}\text { The amount of alkali, } \\
\text { used for titration with } \\
\text { phenolphthalein, ml }\end{array}$ & $\begin{array}{c}\text { Degree of maturity, } \\
{ }^{\circ} \mathrm{Sh} \\
\text { (Shilovich degrees) }\end{array}$ \\
\hline 1 & 0 & \multirow{5}{*}{1} & 0.7 & 0.1 & $75 \pm 0.5$ \\
\hline 2 & 5 & & 1 & 0.2 & $80 \pm 0.6$ \\
\hline 3 & 10 & & 1 & 0.2 & $80 \pm 0.6$ \\
\hline 4 & 15 & & 1 & 0.2 & $80 \pm 0.6$ \\
\hline 6 & 25 & & 1 & 0.2 & $80 \pm 0.6$ \\
\hline 1 & 0 & \multirow{6}{*}{2} & 0.8 & 0.1 & $80 \pm 0.6$ \\
\hline 2 & 5 & & 1.1 & 0.2 & $90 \pm 0.73$ \\
\hline 3 & 10 & & 1.2 & 0.2 & $100 \pm 1.1$ \\
\hline 4 & 15 & & 1.4 & 0.4 & $100 \pm 1.1$ \\
\hline 5 & 20 & & 1.5 & 0.4 & $110 \pm 2.2$ \\
\hline 6 & 25 & & 1.5 & 0.4 & $110 \pm 2.2$ \\
\hline 1 & 0 & \multirow{6}{*}{3} & 0.9 & 0.1 & $85 \pm 0.56$ \\
\hline 2 & 5 & & 1.2 & 0.2 & $100 \pm 1.1$ \\
\hline 3 & 10 & & 1.5 & 0.4 & $110 \pm 2.2$ \\
\hline 4 & 15 & & 1.6 & 0.4 & $120 \pm 2.9$ \\
\hline 5 & 20 & & 1.6 & 0.4 & $120 \pm 2.9$ \\
\hline 6 & 25 & & 1.7 & 0.4 & $130 \pm 1.21$ \\
\hline 1 & 0 & \multirow{6}{*}{4} & 1 & 0.1 & $90 \pm 0.73$ \\
\hline 2 & 5 & & 1.3 & 0.2 & $110 \pm 2.2$ \\
\hline 3 & 10 & & 1.6 & 0.4 & $120 \pm 2.9$ \\
\hline 4 & 15 & & 1.7 & 0.4 & $130 \pm 1.21$ \\
\hline 5 & 20 & & 1.7 & 0.4 & $130 \pm 1.21$ \\
\hline 6 & 25 & & 1.8 & 0.4 & $140 \pm 2.8$ \\
\hline 1 & 0 & \multirow{6}{*}{5} & 1.2 & 0.2 & $95 \pm 0.84$ \\
\hline 2 & 5 & & 1.5 & 0.3 & $120 \pm 2.9$ \\
\hline 3 & 10 & & 1.8 & 0.5 & $130 \pm 1.21$ \\
\hline 4 & 15 & & 1.9 & 0.5 & $140 \pm 2.8$ \\
\hline 5 & 20 & & 1.9 & 0.5 & $140 \pm 2.8$ \\
\hline 6 & 25 & & 2 & 0.5 & $150 \pm 1.74$ \\
\hline 1 & 0 & & 1.4 & 0.3 & $100 \pm 1.1$ \\
\hline
\end{tabular}




\begin{tabular}{|c|c|c|c|c|c|}
\hline 2 & 5 & \multirow{5}{*}{6} & 1.7 & 0.4 & $130 \pm 1.21$ \\
\hline 3 & 10 & & 2 & 0.6 & $140 \pm 2.8$ \\
\hline 4 & 15 & & 2.1 & 0.6 & $150 \pm 1.74$ \\
\hline 5 & 20 & & 2.1 & 0.6 & $150 \pm 1.74$ \\
\hline 6 & 25 & & 2.2 & 0.6 & $160 \pm 4.2$ \\
\hline
\end{tabular}

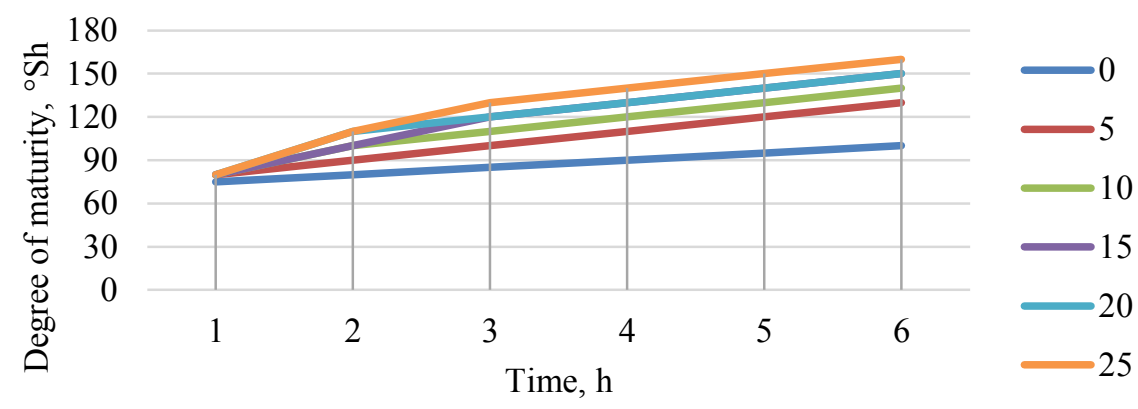

Fig. 1. Change in the magnitude of proteolysis

As a result of the studies, it was found that with an increase in the concentration of the introduced biologically active additive, the value of proteolysis in comparison with the control increases 1.6 times ( $160^{\circ} \mathrm{Sh}$ versus $100^{\circ} \mathrm{Sh}$, respectively). It should be noted that after 6 hours the value of proteolysis, depending on the concentration of the biologically active additive, increased 2 times - the concentration of the biologically active additive is $25 \%$ to the cheese mass; 1.9 times - the concentration of the supplement $20 \%$ to the cheese mass; 1.9 times - the concentration of the supplement $15 \%$ to the cheese mass; 1.8 times the concentration of the supplement is $10 \%$ to the cheese mass; 1.6 times - the concentration of bioadditives $5 \%$ to the cheese mass; control 1.3 times.

An increase in the value of proteolysis indicates the presence in the system of a biologically active functional ingredient of proteolytic enzymes that promote the breakdown of protein into individual peptides, amines, amides, amino acids, while plasticization of the cheese mass occurs, becoming more tender and plastic compared to the control, proteolysis also improves digestibility digested milk protein in comparison with molecules of $\mathrm{CCPhC}$, which increases the biological value of the produced product. However, with an increase in the proteolysis time by more than 4 hours, it causes the release of serum and disruption of the structure of the modified biomass. The most optimal biomodification time is 4 hours, the concentration of the introduced biologically active additive is $15 \%$ to the cheese mass - the proteolysis value is $130^{\circ} \mathrm{Sh}$.

A study of the intensity of acid production is provided, depending on the dose of the introduced functional ingredient. Enzyme $\beta$ - galactosidase - typical enzyme of catabolic $p$ $\beta$-D-galactoside bonds, cleaving off galactoside residues from the non-reducing end of galactosides, followed by hydrolysis of lactose to lactic acid, which contributes to the destabilization of casein micelles, cleaving calcium phosphate from caseinate calcium phosphate complex. The result is the destabilization of casein and the formation of a gel. Many bacteria are active producers of $\beta$ - galactosidase, but this ability is an individual characteristic of each individual strain, which leads to the need to select strains with high productivity of $\beta$ - galactosidase.

The ability to ferment lactose or lactic fermentation activity of lactic acid bacteria is determined by their acid-forming activity in milk, by calculating the lactic acid formed during fermentation.

In the production of new types of food products, an important point is to study the accumulation of lactic acid, to determine the amount of fermented lactose and the index of 
lactic-fermenting activity of proteolytic microflora in the process of fermentation of cheese mass ( $2 \%$ starter culture to cheese mass) with various doses (from $5 \%$ to $25 \%$ ) of the functional ingredient. To ripen the cheese mass, the test samples were placed in a thermostat at a temperature of $18^{\circ} \mathrm{C}$ for 6 hours.

The research results are presented in the table 3 .

Table 3. Study of the intensity of acid formation depending on the dose of barley malt extract applied

\begin{tabular}{|c|c|c|c|c|c|c|}
\hline 竞 & $\begin{array}{c}\text { Content of } \\
\text { Barley malt } \\
\text { extract } \\
\text { (BME), \% }\end{array}$ & 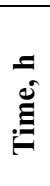 & Acidity, ${ }^{\circ} \mathbf{T}$ & $\begin{array}{l}\text { The amount of } \\
\text { lactic acid }\end{array}$ & $\begin{array}{c}\text { The amount of } \\
\text { fermented lactose }\end{array}$ & $\begin{array}{c}\text { Index of } \\
\text { lacto- } \\
\text { fermentin } \\
\text { g activity }\end{array}$ \\
\hline 1 & 0 & \multirow{5}{*}{1} & 44 & 3.96 & 0.171 & 0.045 \\
\hline 2 & 5 & & 48 & 4.32 & 0.171 & 0.046 \\
\hline 3 & 10 & & 50 & 4.5 & 0.171 & 0.046 \\
\hline 4 & 15 & & 52 & 4.68 & 0.171 & 0.046 \\
\hline 5 & 20 & & 56 & 5.04 & 0.342 & 0.091 \\
\hline 6 & 25 & & 58 & 5.22 & 0.342 & 0.091 \\
\hline 1 & 0 & \multirow{6}{*}{2} & 46 & 4.14 & 0.342 & 0.091 \\
\hline 2 & 5 & & 50 & 4.5 & 0.342 & 0.091 \\
\hline 3 & 10 & & 52 & 4.68 & 0.342 & 0.091 \\
\hline 4 & 15 & & 60 & 5.4 & 0.855 & 0.227 \\
\hline 5 & 20 & & 68 & 6.12 & 1.368 & 0.364 \\
\hline 6 & 25 & & 74 & 6.66 & 1.71 & 0.455 \\
\hline 1 & 0 & \multirow{6}{*}{3} & 48 & 4.32 & 0.513 & 0.136 \\
\hline 2 & 5 & & 52 & 4.68 & 0.513 & 0.136 \\
\hline 3 & 10 & & 56 & 5.04 & 0.684 & 0.182 \\
\hline 4 & 15 & & 64 & 5.76 & 1.197 & 0.318 \\
\hline 5 & 20 & & 72 & 6.48 & 1.71 & 0.455 \\
\hline 6 & 25 & & 84 & 7.56 & 2.565 & 0.682 \\
\hline 1 & 0 & \multirow{6}{*}{4} & 50 & 4.5 & 0.684 & 0.182 \\
\hline 2 & 5 & & 54 & 4.86 & 0.684 & 0.182 \\
\hline 3 & 10 & & 62 & 5.18 & 1.197 & 0.318 \\
\hline 4 & 15 & & 68 & 6.12 & 1.539 & 0.409 \\
\hline 5 & 20 & & 78 & 7.02 & 2.223 & 0.591 \\
\hline 6 & 25 & & 90 & 8.1 & 3.078 & 0.818 \\
\hline 1 & 0 & \multirow{6}{*}{5} & 52 & 4.68 & 0.855 & 0.227 \\
\hline 2 & 5 & & 56 & 5.04 & 0.855 & 0.227 \\
\hline 3 & 10 & & 66 & 5.94 & 1.539 & 0.409 \\
\hline 4 & 15 & & 74 & 6.66 & 2.052 & 0.538 \\
\hline 5 & 20 & & 84 & 7.56 & 2.736 & 0.727 \\
\hline 6 & 25 & & 94 & 8.46 & 3.42 & 0.909 \\
\hline 1 & 0 & \multirow{6}{*}{6} & 54 & 4.86 & 1.026 & 0.273 \\
\hline 2 & 5 & & 58 & 5.22 & 1.026 & 0.273 \\
\hline 3 & 10 & & 72 & 6.48 & 2.052 & 0.545 \\
\hline 4 & 15 & & 80 & 7.2 & 2.565 & 0.682 \\
\hline 5 & 20 & & 90 & 8.1 & 3.249 & 0.864 \\
\hline 6 & 25 & & 98 & 8.82 & 3.762 & 1 \\
\hline
\end{tabular}




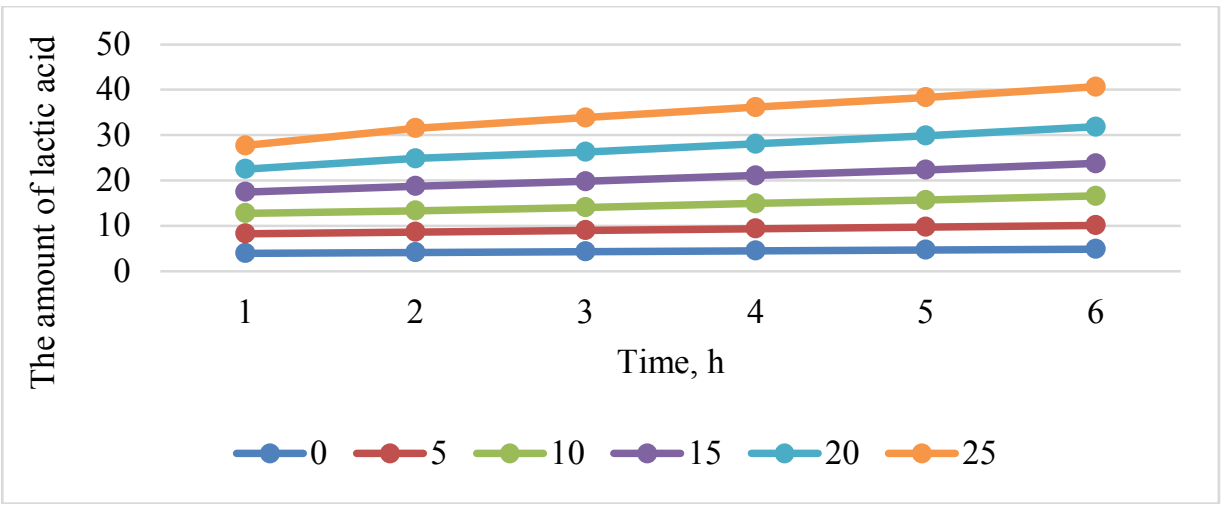

Fig. 2. Study of the accumulation of lactic acid of proteolytic microflora

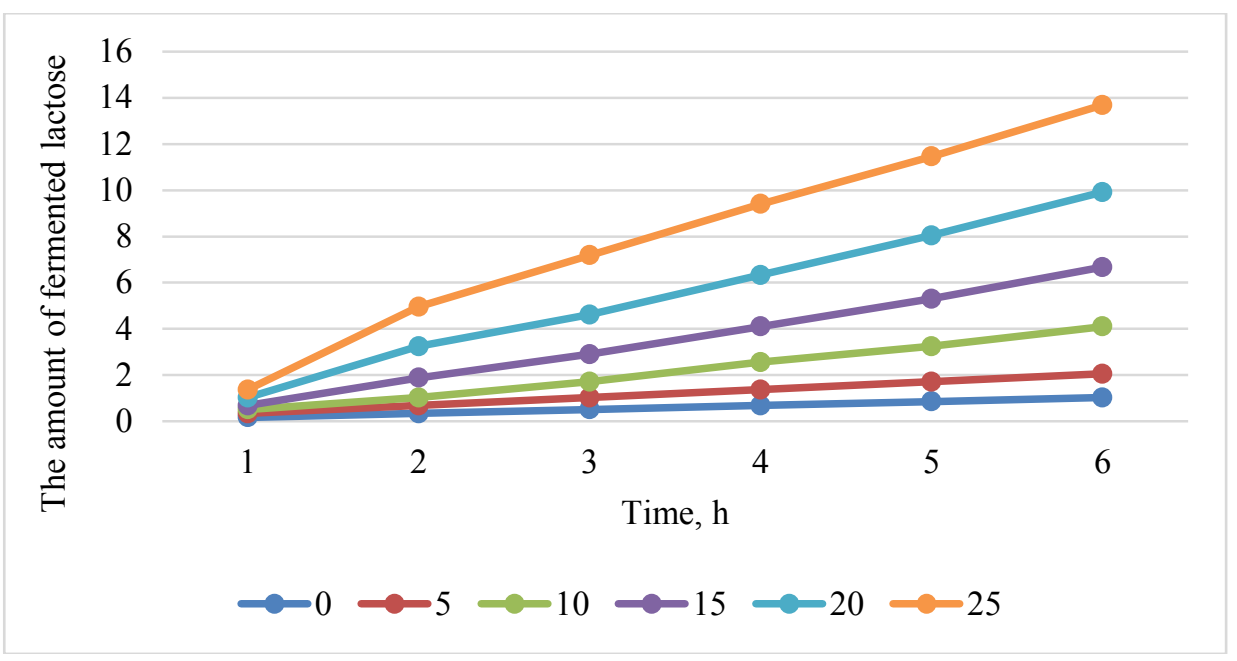

Fig. 3. Study of the amount of fermented lactose of proteolytic microflora

As a result of the studies carried out, the activating effect of the introduced functional additive on the acid formation process was established. The adaptation time of microorganisms in the log phase was reduced by 1.5 times compared to the control, the growth rate of microorganisms in the lag phase increased 1.7 times compared to the control. This is most likely due to the presence of free polysaccharides, vitamins, macro- and microelements, pectins and biologically active substances in the functional ingredient.

With an increase in the amount of the added functional additive, the intensity of acid formation increased, which indicates a symbiosis of probiotic microorganisms and a functional ingredient.

In order to implement of the federal law of the Russian Federation TR/CU 027/2012 the production of lactose-free and low-lactose food products is of particular relevance. The author carried out studies to determine the amount of fermented lactose and the index of lactic fermenting activity.

As a result of the studies, it was found that with an increase in the amount of introduced functional ingredient, the amount of fermented lactose increases by 11 times, the index of lacto-fermenting activity by 11 times. 
Thus, as a result of the studies, it was established that the introduction of a synbiotic (probiotic cultures and a functional ingredient) into the cheese mass increases the biological value of the developed product and allows it to be recommended as a therapeutic and prophylactic food for people suffering from galactosemia, preschool and school children, and the elderly.

The most rational amount of introduced probiotic microflora was chosen - $2 \%$ to the cheese mass; functional ingredient $15 \%$ to the cheese mass, because further increase in the concentration of dietary supplements is impractical due to the deterioration of organoleptic parameters (stratification of the clot, release of serum).

The results of calculations of the amino acid rate of the produced product are shown in the table 4 .

Table 4 .Calculation of the amino acid rate of a cheese product like "Ricotta"

\begin{tabular}{|c|c|c|c|c|c|}
\hline \multirow[b]{2}{*}{$\begin{array}{c}\text { Essential amino } \\
\text { acid }\end{array}$} & \multicolumn{3}{|c|}{$\begin{array}{c}\text { Amino acid content mg per } 1 \\
\text { g of protein }\end{array}$} & \multicolumn{2}{|c|}{ Amino acid score, $\%$} \\
\hline & 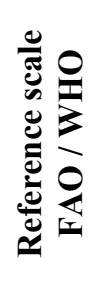 & $\underset{ٍ}{\stackrel{0}{0}}$ & 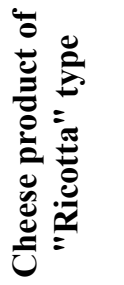 & $\underset{\stackrel{0}{0}}{\stackrel{0}{\Xi}}$ & 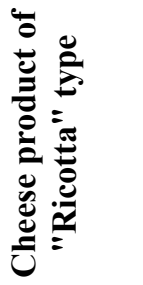 \\
\hline Valine & 50 & 692 & 820 & 122.48 & 139 \\
\hline Isoleucine & 40 & 589 & 848 & 130.31 & 179.7 \\
\hline Leucine & 70 & 1221 & 1272 & 154.4 & 154 \\
\hline Lysine & 55 & 1338 & 460 & 215.3 & 70.8 \\
\hline Methionine & 22 & 281 & 250 & 113 & 96.3 \\
\hline Threonine & 40 & 517 & 620 & 114.4 & 131.4 \\
\hline Phenylalanine & 28 & 556 & 690 & 175.7 & 208.84 \\
\hline
\end{tabular}

Evaluating the quality of proteins produced by the amino acid score method, it can be noted that they are distinguished by a good balance, practically for all essential amino acids, the rate is above $100 \%$. The limiting amino acid of the Ricotta cheese product is lysine (score 70.8\%), control is methionine (score 113\%). The amino acid score of phenylalanine is 1.2 times higher than in the control $(208.84 \%$ versus $175.7 \%$, respectively); isoleucine 1.4 times (179.7\% versus $130.31 \%$, respectively); valine by 1.1 times (139\% versus 122.48 , respectively); threonine by 1.2 times $(131.4 \%$ versus $114.4 \%$, respectively). However, the amino acid score of methionine is 1.2 times lower than in the control (96.3\% versus $113 \%$, respectively), lysine is 3 times lower $(70.8 \%$ versus 215.3 , respectively).

As a result of the analysis of the biological value of the produced product, it can be concluded that the amino acid composition of the produced product is better balanced in terms of the main essential amino acids compared to the control. Thus, the introduction of a biologically active phytoextract into the formulation improves the functional properties of the product.

As a result of this work, the following scientific and practical conclusions were formulated:

1. The possibility of using barley malt extract in the production of an enriched cheese product in order to increase its nutritional and biological value has been scientifically and experimentally substantiated. 
2. As a result of the research, the most rational technological scheme for the production of barley malt extract was established.

3. The macroelement and vitamin composition of barley malt extract has been investigated. The data of the conducted research allow the use of barley malt extract as an effective dietary supplement that increases the nutritional value of dairy products, bringing their chemical composition in terms of basic nutrients closer to a balanced nutrition formula.

4. As a result of the conducted studies, it was found that the most rational dose of the introduced starter microflora is $2 \%$.

5. In order to create an enriched cheese product, rational parameters of the process of thermoacid deposition of the mixture components were established (deposition temperature $90-95^{\circ} \mathrm{C}$ with an exposure of 40 minutes). Acid whey (titratable acidity $1700 \mathrm{~T}$ ) was chosen as a coagulant.

6. To ensure the most complete yield of the product with the lowest raw material costs, the most rational acidity of the mixture was established at $95^{\circ} \mathrm{T}(\mathrm{pH} \mathrm{4,2)}$.

7. The most rational normalized milk and whey mixture (60\% whey and $40 \%$ milk) was formulated to obtain a good tender, slightly thickened curd and a moderately sour taste, cost effective, resource-saving.

8. The most rational ratio of the cheese mass and the added functional ingredient has been experimentally established - 85:15.

9. The most optimal biomodification time is 4 hours, the concentration of the introduced biologically active additive is $15 \%$ to the cheese mass - the proteolysis value is $130^{\circ} \mathrm{Sh}$.

10. The technology of an enriched cheese product of the "Ricotta" type with the use of barley malt extract has been developed.

\section{References}

1. J. Meltretter, J. Wüst, D. Dittrich, J. Lach, J. Ludwig, J. Eichler, M. Pischetsrieder, Untargeted Proteomics-Based Profiling for the Identification of Novel ProcessingInduced Protein Modifications in Milk. Journal of Proteome Research, 19(2), 805-818 (2020)

2. Y. Zhang, Y. Xia, P. F.-H. Lai, X. Liu, Z. Xiong, J. Liu, L. Ai, Fermentation conditions of serine/alkaline milk-clotting enzyme production by newly isolated Bacillus licheniformis BL312. Annals of Microbiology, 69(12), 1289-1300 (2019)

3. X. Zhao, M. Cai, Z.-J. Yang, T.-Q. Luo, A. Sarwar, S. Megrous, T. Aziz, Z.-N. Yang, Purification and characterization of a novel milk-clotting enzyme produced by Bacillus amyloliquefaciens GSBa-1. European Food Research and Technology, 245(11), 24472457 (2019)

4. M. Rusin, E. Årsand, G. Hartvigsen, Functionalities and input methods for recording food intake: a systematic review. Int. J. Med. Inform., 82, 653- 664 (2013)

5. K. Cho, N. G. Mahieu, S. L. Johnson, G. J. Patti, After the feature presentation: technologies bridging untargeted metabolomics and biology. Curr. Opin. Biotechnol., 28, 143- 148 (2014)

6. L. Brennan, NMR-based metabolomics: from sample preparation to applications in nutrition research. Prog. Nucl. Magn. Reson. Spectrosc., 83, 42- 49 (2014)

7. G. Pimentel, D. Burnand, L. H. Münger, F. P. Pralong, N. Vionnet, R. Portmann, G. Vergères, Identification of Milk and Cheese Intake Biomarkers in Healthy Adults Reveals High Interindividual Variability of Lewis System-Related Oligosaccharides. J. Nutr., 150, 1058-1067(2020) 
8. L. H. Münger, A. Trimigno, G. Picone, C. Freiburghaus, G. Pimentel, K. J. Burton, F. P. Pralong, N. Vionnet, F. Capozzi, R. Badertscher, G. Vergères, Identification of Urinary Food Intake Biomarkers for Milk, Cheese, and Soy-Based Drink by Untargeted GC-MS and NMR in Healthy Humans. J. Proteome Res., 16, 3321- 3335 (2017)

9. G. Pimentel, K. J. Burton, U. von Ah, U. Bütikofer, F. P. Pralong, N. Vionnet, R. Portmann, G. Vergères, Metabolic Footprinting of Fermented Milk Consumption in Serum of Healthy Men. J. Nutr., 148, $851-860$ (2018)

10. R. B. Magenis, E. S. Prudêncio, L. Molognoni, H. Daguer, A Control Method To Inspect the Compositional Authenticity of Minas Frescal Cheese by Gel Electrophoresis. Journal of Agricultural and Food Chemistry, 62(33), 8333-8339 (2014)

11. H. Hillmann, T. Hofmann, Quantitation of Key Tastants and Re-engineering the Taste of Parmesan Cheese. Journal of Agricultural and Food Chemistry, 64(8), 1794-1805 (2016)

12. G. Kozlov, et al., Technologically significant properties of municipal solid waste compost. E3S Web of Conferences, 175, 12015 (2020) doi: $10.1051 / \mathrm{e} 3$ sconf $/ 202017512015$

13. M. Kuroda, K. Sasaki, J. Yamazaki, Y. Kato, T. Mizukoshi, Quantification of the kokumi peptide, $\gamma$-glutamyl-valyl-glycine, in cheese: Comparison between cheese made from cow and ewe milk. Journal of Dairy Science, 103(9), $7801-7807$ (2020)

14. J. Yang, W. Bai, X. Zeng, C. Cui, Gamma glutamyl peptides: The food source, enzymatic synthesis, kokumi-active and the potential functional properties - A review. Trends in Food Science \& Technology, 91, 339-346 (2019)

15. Y. Zhang, Y. Ma, Z. Ahmed, W. Geng, W. Tang, Y. Liu, H. Jin, F. Jiang, J. Wang, Y. Wang, Purification and identification of kokumi-enhancing peptides from chicken protein hydrolysate. International Journal of Food Science \& Technology, 54(6), 2151-2158 (2019) 